\title{
Screening of Bioluminescent Bacterial Strains for Developing Novel Toxicity Sensing Beads
}

\author{
Neha Thakre ${ }^{1}$, Arti Shanware ${ }^{1, *}$ \\ 1 Rajiv Gandhi Biotechnology Centre, L.I.T Premises, R.T.M. Nagpur University \\ Nagpur - 440033 (M.S), India \\ * Corresponding author: artishanware@gmail.com; Tel.: + 91712 2552080,+91 \\ 9823018963; Fax: + 91712 2552080, +91 712 2560620; \\ E-mail address: thakre.neha@yahoo.com
}

Published: 1 June 2014

\begin{abstract}
The present study targets to explore the diverse marine ecosystems of Dapoli beach, Kokan, Maharashtra, India (Asia) for probable isolation of novel bioluminescence bacterial species. Further, these isolates were analysed for their potential use as a biological indicators. Preliminary screening of pure isolated bioluminescent bacteria was done by morphological \& biochemical techniques. Further the molecular characterization was accomplished by the $16 \mathrm{~s}$ rDNA analysis. The $16 \mathrm{~S}$ rDNA amplified genes were sequenced which further analysed by BLAST for similarity search conforming that DM, DS designated isolates were Vibrio fischeri \& Photobacterium phosphoreum respectively. Phylogenetic analysis was done with the aid of MEGA 4.0 software. Further, the lux genes were also amplified as a bioluminescent bacterial strain specific marker gene .Furthermore, the biosensing capability of isolates was investigated against various forms of heavy metals as well as antibiotics. Correlating luminescence pattern of isolates against toxic pollutants generated during proposed investigations would be of great help to develop an efficient, rapid water pollution monitoring biosensor. Finally, these bacterial strains were immobilized in varied percentage of sodium alginate and concentrations of calcium chloride, respectively. $1 \%$ sodium alginate with $0.1 \mathrm{M} \mathrm{CaCl}$ is found to be most appropriate immobilization material. Bioluminescent beads were tested against various
\end{abstract}


toxic heavy metal compounds. These bioluminescent beads are reusable for atleast two times. This bioluminescence based assay would prove to be the secure, rapid, and responsive monitoring system which could detect a wide variety of heavy metal pollutants.

Keywords: Bioluminescence; biobeads; bioluminescent bacteria; biosensor; immobilization; lux genes

\section{Introduction}

Bioluminescence, a light emission by living organisms abundantly distributed from marine to terrestrial environment plays a vital role in ecological balance. This versatile group of organisms has grabbed attention of researchers all over the world (1). An application of bioluminescence is being studied for varied biosciences field including cancer diagnostics, biomarkers \& reporter systems, biosensors etc. Luminescent bacteria convert chemical energy to light energy with the help of key enzyme luciferase, aldehyde derivatives $\&$ oxygen molecules (2). Any kind of pollutant results in deprivation of oxygen content of water sample, which in turn interferes in bioluminescence production by bacteria either completely or partially. This decrease in luminescence in presence of pollutant makes luminescent bacteria a very important biosensing element to develop a real-time water pollution monitoring system (3). Even though various studies had been carried out till date regarding broader distribution and abundance of luminous bacteria in marine environment, still facts regarding population dynamics, ecological utility, niche relationships and molecular studies remain inadequately explored, especially in Indian coastal regions (4). The present investigation is an attempt towards exploring versatile luminescent bacterial diversity distributed in coastal region of Dapoli beach, Maharashtra, India (Asia). Further the utilization of unique - luminescent property of these bacterial strains as an environmental biomarker system has been studied extensively.

\section{Experimental Section}

\subsection{Sampling and isolation of Luminescent Bacterial Strains}

To achieve the objectives of this investigation, samples were collected from marine water sources of Dapoli beach located in Kokan, Maharashtra, India (Asia) using sterile autoclaved dilution bottles. Water sampling was performed in the month of January, 2013. Around 300$500 \mu \mathrm{L}$ of water sample was spread plated on modified nutrient agar plates in triplicates for each sample (5). Luminous colonies were observed on plate after $24 \mathrm{hrs}$ of incubation at $22^{\circ}$ $\mathrm{C}$ in dark room. Highly luminescent purified colonies were picked for performing quadrant streak plating. These purified isolates were studied for their morphological as well as biochemical characterization by standard Bergey's Manual of Systematic Bacteriology (6). 


\subsection{Molecular characterization of luminescent bacteria}

Bacterial genomic DNA isolation was performed using Axyprep Bacterial Genomic DNA miniprep kit (Genaxy) which was confirmed by running a gel electrophoresis of $0.8 \%$ agarose gel. DNA quantification was done by NanoDrop 1000 Spectrophotometer (ThermoScientific). With the help of universal primers 8F: 5"AGA GTT TGA TCC TGG

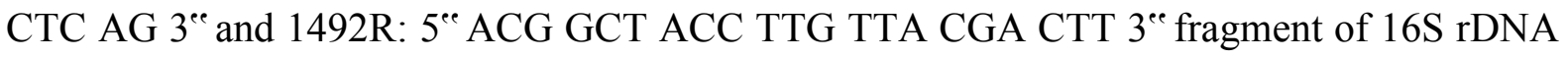
gene was amplified. For bacterial $16 \mathrm{~S}$ rDNA amplification parameters - an initial denaturation of $94^{\circ} \mathrm{C}$ for $3 \mathrm{~min}$., 30 cycles of $\left(94^{\circ} \mathrm{C} 30 \mathrm{sec}\right.$., $52.7^{\circ} \mathrm{C} 30 \mathrm{sec}$, and $72^{\circ} \mathrm{C} 1.30$ min), final Extension of $72^{\circ} \mathrm{C}$ for $5 \mathrm{~min}$. In silico analysis of $16 \mathrm{~S}$ rDNA sequences of isolates under present investigation was performed using BLAST (Basic Local Alignment Search Tool) \& MEGA 4.0 software.

\subsection{Heavy metal $\&$ antibiotic tolerance}

The sensitivity or resistance nature of isolates towards various antibiotics \& heavy metals was tested on bioluminescent bacteria by disc diffusion method. After overnight incubation, plates were observed for the zone of inhibition.

\subsection{Immobilization of luminescent isolates}

Fabrication of bioluminescent beads was achieved by dissolving bacterial pellet of overnight grown luminescent culture in varied percentage of sodium alginate by weight. The bacterial culture-alginate mixture was dropped from a height of $20 \mathrm{~cm}$ into $1000 \mathrm{ml} 0.15 \mathrm{M}$, $0.1 \mathrm{M}, 0.05 \mathrm{M} \mathrm{CaCl} 2$, a crosslinking solution. Bead formation was achieved at room temperature as soon as the sodium alginate drops come in direct contact with the calcium chloride solution .The hardening of beads was achieved in 1-2 hours. The beads were washed with a fresh $0.1 \mathrm{M}$ crosslinking solution as well as stored in same at $4^{\circ} \mathrm{C}$.

\subsection{Luminometeric assay}

The beads of bioluminescent bacteria were exposed to various concentration of heavy metals [Mercuric chloride $\left(\mathrm{HgCl}_{2}\right)$; Lead nitrate $\left(\mathrm{Pb}\left(\mathrm{NO}_{3}\right)_{2}\right)$; Copper sulfate $\left(\mathrm{CuSO}_{4}\right)$; Zinc sulfate $\left(\mathrm{ZnSO}_{4}\right)$; Arsenic trioxide $\left.\left(\mathrm{As}_{2} \mathrm{O}_{3}\right)\right]$ and few pharmaceutical pollutants viz. antibiotics [Gentamicin (50 mcg); Ampicillin (10 mcg); Vancomycin (30 mcg); Penicillin G (10 mcg); Methicillin $(10 \mathrm{mcg})$; Nalidixic acid $(100 \mathrm{mcg})$; Kanamycin $(30 \mathrm{mcg})]$. Before addition of pollutant beads were activated for $30 \mathrm{mins}$ in nutrient broth. After 5 minutes of pollutant exposure luminescence was measured. Glo Max ${ }^{\circledR}$ Luminometer (Promega) were used to measure the luminosity as relative luminescence unit. 


\section{Results and Discussion}

By standard sampling \& purification methodology highly luminescent colonies, designated as DM, DS strains were isolated (Figure 1). Bright field microscopy indicated isolates were gram negative. During biochemical characterization samples were observed to be different in their carbohydrates utilization activity. Isolate designated as DM was found to be negative for producing gelatinase and amylase which suggest relatedness of DM isolate to Vibrio fischeri. Both strains showed positive results for both oxidase as well as catalase test.

Figure 1. Purified Luminescent colonies A- DM isolate; B- DS isolate

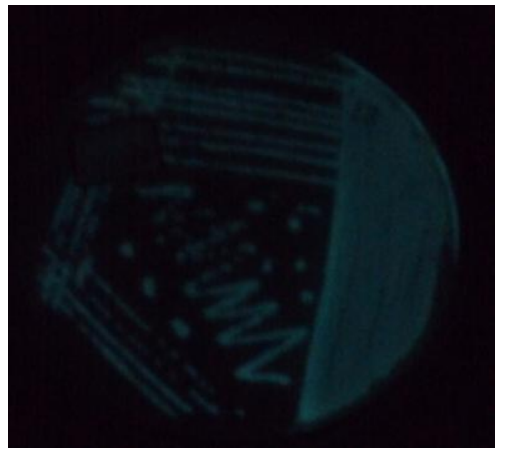

A

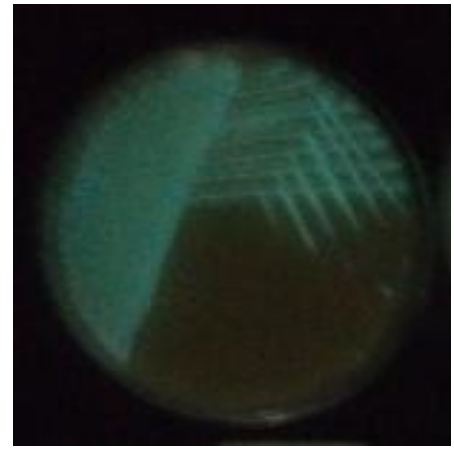

B

PCR amplicon bands of 1033 bp, 1405bp was observed for both DM \& DS isolates respectively when resolved on Agarose Gel (Figure.2). The PCR amplicon was purified to remove contaminants. Consensus sequences of $16 \mathrm{~S}$ rDNA gene were generated from forward and reverse sequence data using aligner software. The 16S rDNA gene sequence was subjected to BLAST with the nrdatabase of NCBI genbank database through which first ten sequences with maximum identity score were selected and aligned using multiple alignment software program Clustal W. Distance matrix was generated using RDP database. The phylogenetic tree was constructed using MEGA 4.

Figure 2. Gel Image of 16SrDNA amplicons of DM \& DS isolates ( Lane 1: DM isolate; Lane 2: DS isolate ; Lane 3: DNA marker)

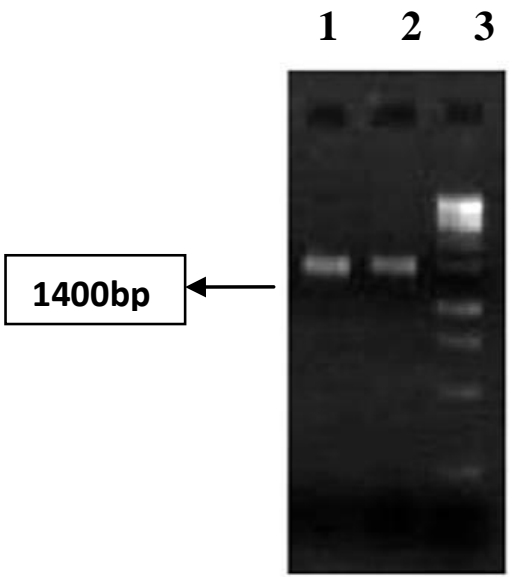


Based on Phylogenetic analysis, sequence obtained from DM isolate was identified as Vibrio fischeri 16S ribosomal RNA gene. Dendrogram (Figure.3) also illustrates close association of DM isolate sequence with Vibrio sp. VH1 $16 \mathrm{~S}$ ribosomal RNA gene. The other sequences selected Vibrio sp. SW231 16S ribosomal RNA gene, Vibrio sp. LC1-239 gene for $16 S$ ribosomal RNA, Vibrio sp. LC1-194 gene for $16 S$ ribosomal RNA, Vibrio sp. L40 $16 S$ ribosomal RNA gene, Vibrio parahaemolyticus gene for $16 S$ rRNA, strain: NBRC 12711, Vibrio sp. BFLP-10 partial 16S rRNA gene, strain BFLP-10, Vibrio sp. Ex97 16 S ribosomal $R N A$ gene and Vibrio harveyi strain S-38 $16 S$ ribosomal RNA gene though homologous in nature, do not share the common evolutionary branch with the target sequence. Further according to the Phylogenetic analysis, DS isolate sequence was identified as Photobacterium $s p$. LBS5 16S ribosomal RNA gene Dendrogram (Figure.4) also illustrates close association of DS sequence with Photobacterium sp. CECT 7614 partial 16S rRNA gene, Photobacterium ganghwense strain 7-4-2 16S ribosomal RNA gene and Photobacterium halotolerans strain MACL01 16S ribosomal RNA. They share maximum sequence identity with query sequence. The other sequences selected like Photobacterium $s p$. enrichment culture clone DF228 16S ribosomal RNA gene, Photobacterium sp. D1-2 16S ribosomal RNA gene, Photobacterium sp. PaD2.14 16S ribosomal RNA gene, Photobacterium sp. JSA04 16S ribosomal RNA gene and Photobacterium sp. 34E11 16S ribosomal RNA gene though homologues in nature they do not share the common evolutionary branch.

Figure 3. Phylogenetic tree of $16 \mathrm{~S}$ rRNA gene of $V$. fischeri with close homologs

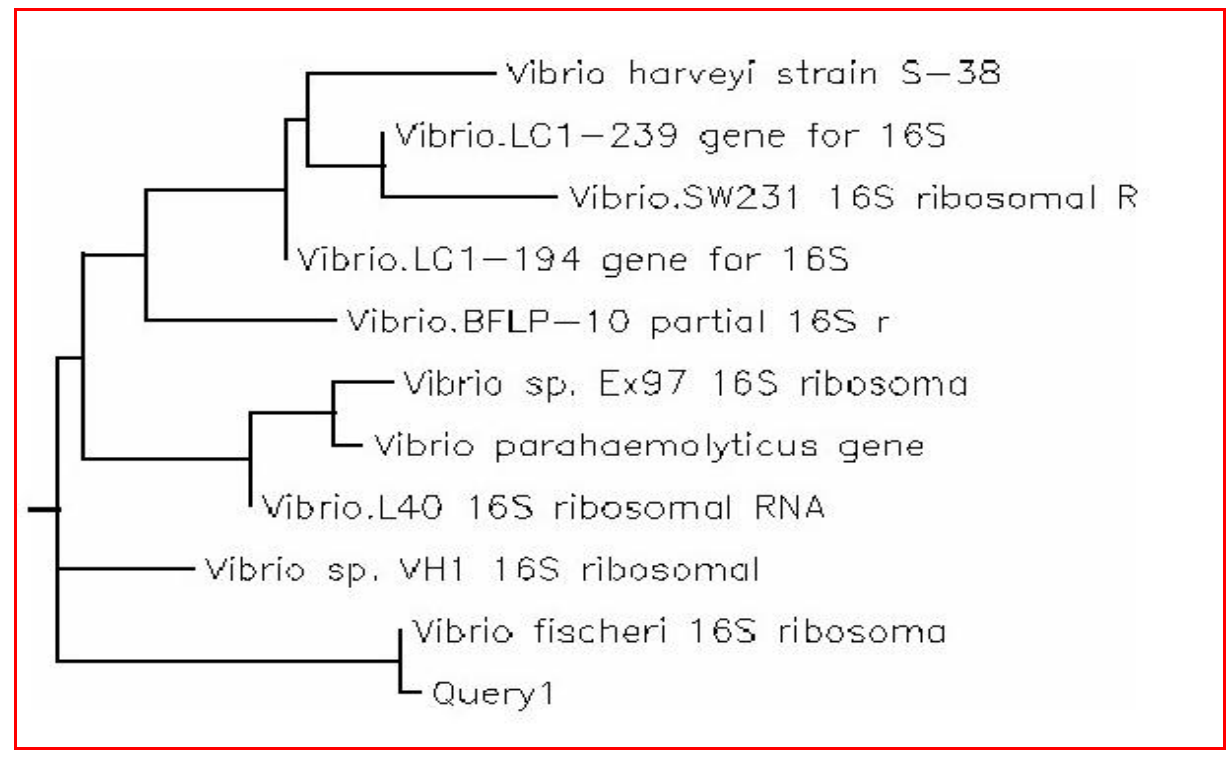


Figure 4. Phylogenetic tree of $16 \mathrm{~S}$ rRNA gene of Photobacterium sp. LBS5 with close homologs.

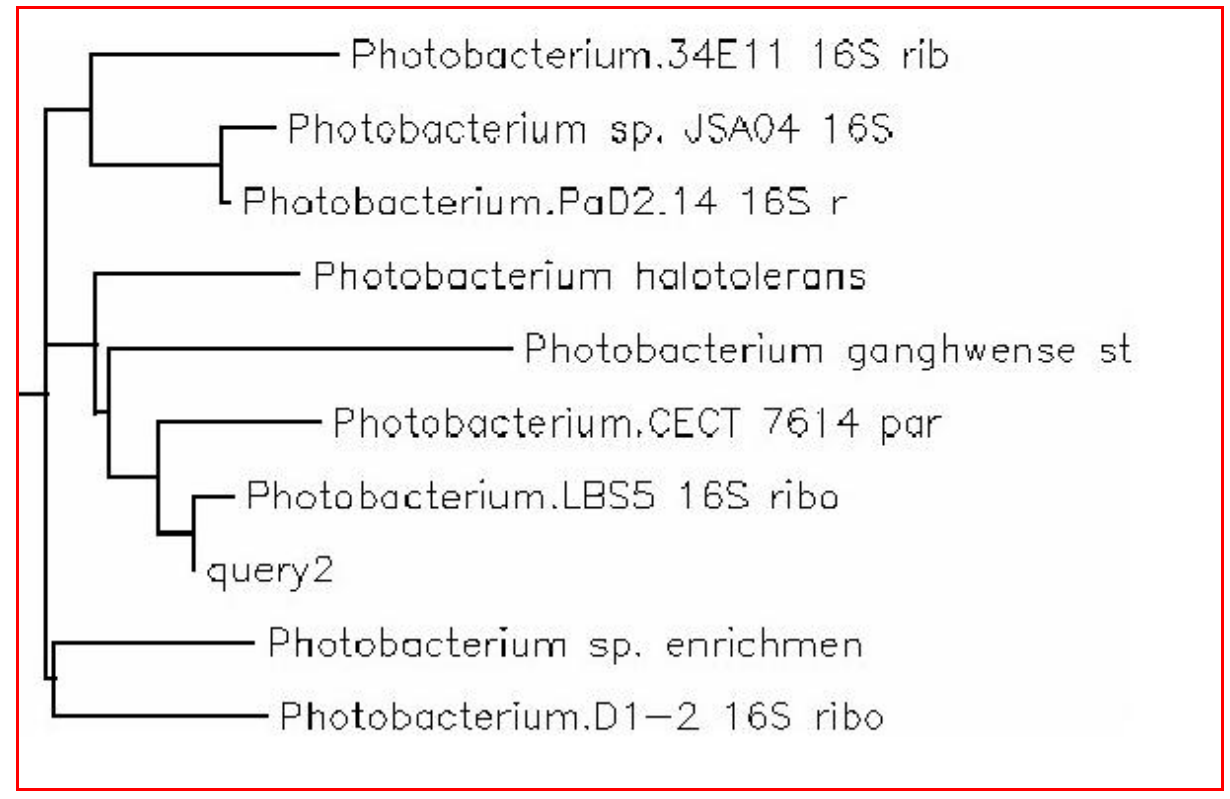

Bioluminescent strains- Vibrio fischeri, Photobacterium sp. isolated during present investigation were immobilized with varied percentage of sodium alginate ( $1 \%, 2 \%, 3 \%)$ and concentrations of calcium chloride $(0.15 \mathrm{M}, 0.1 \mathrm{M}, 0.05 \mathrm{M})$, respectively. Successful immobilization was achieved with $1 \%$ sodium alginate \& $0.1 \mathrm{M} \mathrm{CaCl}_{2}$. Bioluminescent beads were tested against various toxic heavy metals, antibiotic compounds. Gradual decrease in luminescence of beads was observed with increasing toxicity of pollutant. Luminescent beads of both strains showed prominent changes in luminescence when treated with various concentrations of Mercuric chloride $\left(\mathrm{HgCl}_{2}\right)$; Copper sulfate $\left(\mathrm{CuSO}_{4}\right)$; Zinc sulfate $\left(\mathrm{ZnSO}_{4}\right)$; Arsenic trioxide $\left(\mathrm{As}_{2} \mathrm{O}_{3}\right)$. On other hand complete lysis of cells entrapped in beads after treatment with Lead nitrate $\left(\mathrm{Pb}\left(\mathrm{NO}_{3}\right)_{2}\right)$ was observed for both strains, thus no luminescence was observed. All antibiotics at respective concentration $(\mathrm{mcg})$ showed decrease in luminescence as compared to control beads. Only Ampicillin was found to be increasing luminescence of bacterial beads as compared to control beads which proves that it could act as an inducer of luminescence reaction. Biobeads were found to be reusable atleast twice with viability of two months, if stored at $4^{\circ} \mathrm{C}$ in $0.1 \mathrm{M}$ crosslinking solution.

\section{Conclusions}

Present investigations could certainly facilitate up-gradation of luminescent bacterial diversity data of Indian coastal regions. The current studies have explored luminescent bacterial strains which exhibit novel heavy metal and pharmaceutical pollutants sensing ability. These luminescent bacterial strains show "light off" strategy i.e. decrease in luminescence with increasing toxicant concentration. Biobeads fabrication during present study is a preliminary attempt towards exploring novel pollution sensing assay. These strains 
have shown remarkable sensitive towards toxicity present in water samples and therefore they could be used as potential biosensing elements for developing an on-site pollution monitoring sensor.

\section{Acknowledgments}

The financial support under the Major research project sponsored by University Grant of Commission, Govt. of India, New Delhi is gratefully acknowledged.

\section{Author Contributions}

„Arti Shanware"e has designed the study, protocol and conducted the literature survey. „Neha Thakree carried out the isolation \& characterization studies with toxicity profiling of strains under present studies. All authors participated in manuscript writing and approved the final manuscript.

\section{Conflicts of Interest}

The authors declare no conflict of interest.

\section{References}

1. N.Ramaiah, D.Chandramohan. Bacterial bioluminescence in marine pollution assessment. Ocean Technology: perspectives, pg.967-980

2. Meighen E. Autoinduction of light emission in different species of bioluminescent bacteria. Luminescence 1999: 14(1): 3-9

3. Badar U, Shoeb E, Daredia K, Shawar D, Akhtar J, Ansari M. Screening and characterization of luminescent bacterial strain. J Basic Appl Sci. 2012;8:602-606.

4. K. J. Budsberg, C. F. Wimpee and J. F. Braddock. Isolation and identification of Photobacterium phosphoreum from an Unexpected Niche: Migrating Salmon. Appl. Environ. Microbiol. 2003, Vol. 69, No. 11 pg. 6938-6942

5. Shanware, A.S., Thakre, N.A. \& Pande, S.S. (2013). Isolation and characterization of novel marine luminescent bacteria from Diu beach, India. Journal of Pharmacy Research, Vol. 7, pp.529-533

6. G. George M. Bergey's Manual of Systematic Bacteriology. 2nd ed. 2005.

(C) 2014 by the authors; licensee MDPI, Basel, Switzerland. This article is an open access article distributed under the terms and conditions of the Creative Commons Attribution license (http://creativecommons.org/licenses/by/3.0/). 